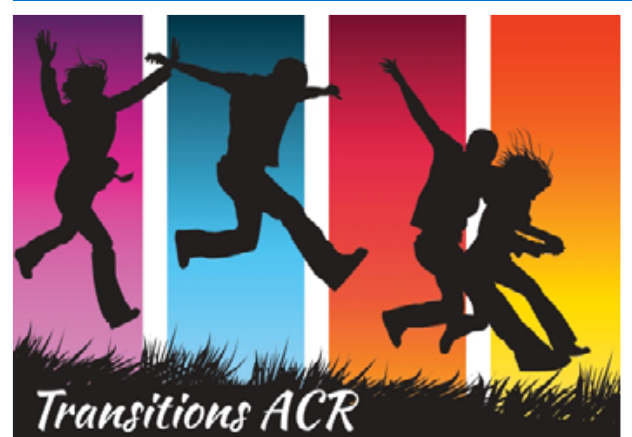

Vol 18 Issue 5

\title{
Can I Bring My Emotional Support Animal to College with Me?
}

\section{Reminder about what an ESA is.}

$\Lambda \mathrm{n}$ Emotional Support Animal (ESA) is an animal that provides therapeutic benefit (e.g., emotional support, comfort, companionship) to a person with a mental health or psychiatric disability (such as a serious mental health condition). An ESA is not considered a Service Animal, but under U.S. law, an emotional support animal is also not considered a pet and is generally not restricted by the type of animal., 2 Any domesticated animal may be considered as an ESA (e.g., cats, dogs, mice, rabbits, birds, hedgehogs, rats, minipigs, ferrets, etc.) and they can be any age. However, an ESA must be able to be manageable in public and does not create a nuisance.

ESA's do not perform specific tasks, instead it is the presence of the animal that relieves the symptoms associated with a person's serious mental health condition. For a person to legally have an emotional support animal (ESA), the owner must be considered to have a qualifying mental health or psychiatric disability by a licensed mental health professional (e.g., therapist, psychologist,

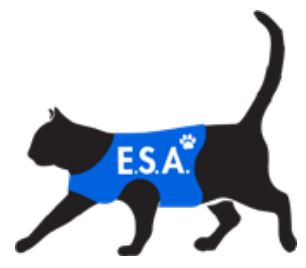
Can I bring an ESA with me to college?
Yes! The Fair Housing Act (FHA) says that "Hous- ing providers cannot refuse to make reasonable accommodations in rules, policies, practices, or services when such accommodations may be necessary to afford a person with a disability the equal opportunity to use and enjoy a dwell- ing." 3 This means that colleges and universities must allow ESAs in housing, even if there is a no-pet policy.

psychiatrist, etc.), which is documented by a properly formatted prescription letter. The difference between a legitimate ESA and a pet is the letter from your licensed mental health professional.

(i) To learn more, see our Emotional Support Animals: The Basics tip sheet.

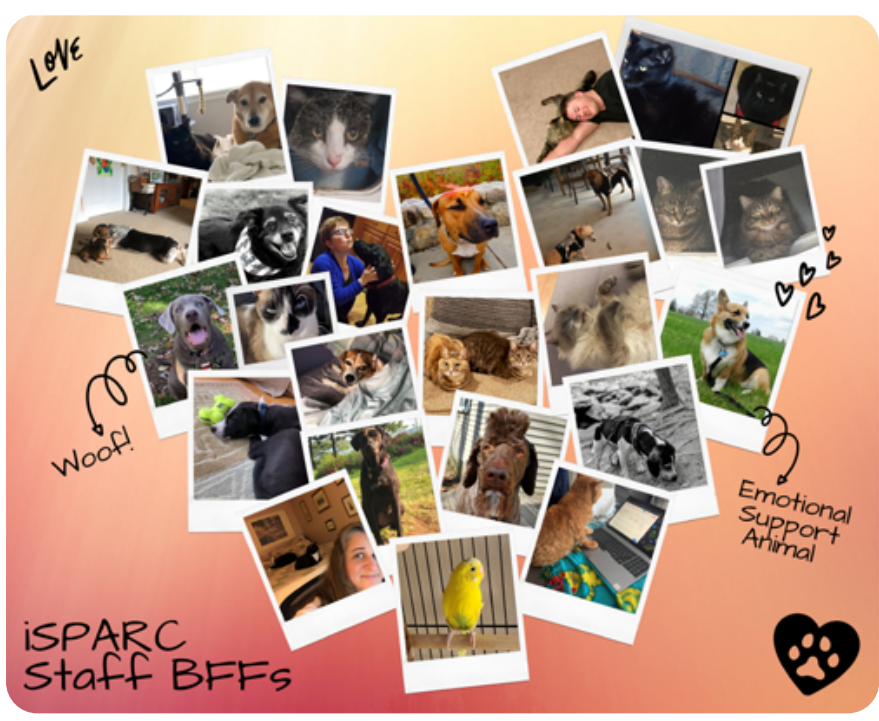

\section{How do I bring an ESA with me to college?}

Policies vary from school to school and it is important to learn about your school's specific policy regarding ESAs. Typically, the process begins in the school's office of disability services. The disability office will ask for documentation of a disability and a letter from a licensed mental health professional stating that an ESA is needed. Some schools may have additional requirements such as the length of time that you have been a patient of the mental health professional. The school might ask to see documentation of veterinarian visits, relevant vaccinations, or other evidence that your animal is healthy and being taken care of properly. 
What else do I need to do before I bring my ESA on campus?

Emotional support animals are considered a housing accommodation, and therefore you may also need to communicate directly with your school's housing office. You might need to communicate with other offices (e.g., campus security) and individuals (e.g., your resident advisor and/or students you live with) about the logistics of having an animal on campus. Schools have different rules about different kinds of animals - bringing a rabbit onto a campus looks very different from bringing a dog, pig, or mini horse. For example, owners of dogs may be asked to register their dog with the town/city in which the school is located.

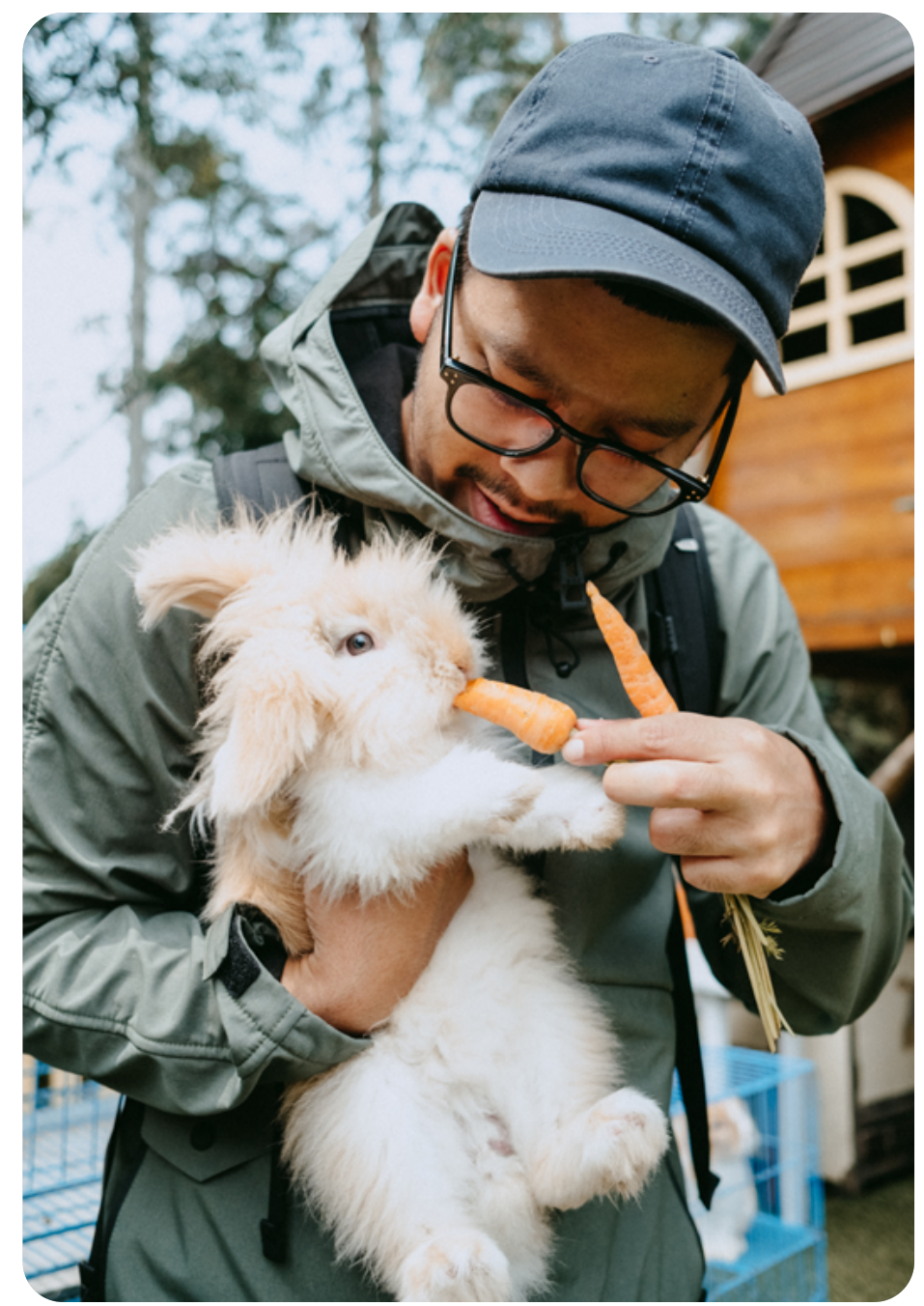

\section{Where can I bring my animal?}

\begin{tabular}{|l|c|c|c|}
\hline Can I bring my animal with me... & ESA & Service Animal & Pet \\
\hline $\begin{array}{l}\text { To my college or university } \\
\text { housing? }\end{array}$ & Yes & Yes & $\begin{array}{c}\text { Only if the school } \\
\text { allows pets }\end{array}$ \\
\hline $\begin{array}{l}\text { To housing with a } \\
\text { no-pet policy? }\end{array}$ & Yes & Yes \\
\hline $\begin{array}{l}\text { To a restaurant? } \\
\text { Only if the restaurant } \\
\text { allows pets }\end{array}$ & Yes & $\begin{array}{l}\text { Only if the restaurant } \\
\text { allows pets }\end{array}$ \\
\hline $\begin{array}{l}\text { On an airplane? } \\
\text { Depends on the } \\
\text { airline's policy* }\end{array}$ & Yes & $\begin{array}{l}\text { Only if the airline } \\
\text { allows pets (rare) }\end{array}$ \\
\hline $\begin{array}{l}\text { "Yes" means that you are legally allowed to bring your animal into the space, but in most cases, you will need to } \\
\text { provide some form of documentation of your need for the accommodation (i.e., your animal). Additionally, this does } \\
\text { not mean that you cannot be asked to remove your animal from the space if it does not comply with the rules of the } \\
\text { space or poses health or safety risks to others. } \\
\text { * Contact the airline directly to ask about their ESA and pet policies. }\end{array}$ \\
\hline
\end{tabular}




\section{Takeaways}

- Emotional support animals can provide therapeutic benefit to individuals with serious mental health conditions.

- Emotional support animals $\neq$ service animals, therapy animals, or pets.

- $\quad$ ESAs can benefit individuals in a variety of ways.

- If you think an ESA would benefit you, talk with your mental health professional.

- You will need documentation to bring an ESA places with you.

- $\quad$ ESAs are allowed on college campuses with proper documentation and communication.

- It's always a good idea to communicate openly and ahead of time when bringing an ESA to a new place.

\section{Our Other Relevant Materials}

- Emotional Support Animals: The Basics tip sheet

(https://escholarship.umassmed.edu/pib/vol18/iss4/7)

- Our ESA webpage

(https://www.umassmed.edu/TransitionsACR/resources/emotional-support-animals-101/)

- Having an Emotional Support Animal at College. Meet Anwyn and Yoda. (https://youtu.be/o_ZEpMR3BAI)

- $\quad$ Comeback TV (CBTV) Episode 3 | Therapy Animals: The Types and Your Rights (https://youtu.be/BbFMN2A9Wgg)

\section{References}

1. U.S. Department of Housing and Urban Development. (2020, January 28). Assessing a person's request to have an animal as a reasonable accommodation under the Fair Housing Act. Retrieved from https://www.hud.gov/sites/dfiles/PA/documents/ HUDAsstAnimalNC1-28-2020.pdf

2. Wisch, R. F. (2015). FAQs on emotional support animals. Animal Legal \& Historical Center. Michigan State University. Retrieved 07 February 2021. https://www.animallaw.info/article/faqs-emotional-support-animals

3. U.S. Department of Housing and Urban Development. (n.d.). Assistance animals. Retrieved from https://www.hud.gov/ program_offices/fair_housing_equal_opp/assistance_animals

Recommended Citation: Gatesy-Davis, A. (2021). Can I Bring My Emotional Support Animal to College with Me? Worcester, MA: University of Massachusetts Medical School, Department of Psychiatry, Implementation Science and Practice Advances Research Center (iSPARC), Transitions to Adulthood Center for Research.

The contents of this tip sheet were supported in part under grants with funding from the National Institute on Disability, Independent Living, and Rehabilitation Research, (NIDILRR), United States Departments of Health and Human Services (NIDILRR grant number 90RTEMO005, The Learning and Working Transitions RRTC). NIDIL$\mathrm{RR}$ is a Center within the Administration for Community Living (ACL), Department of Health and Human Services (HHS). The contents of this tip sheet do not necessarily represent the policy of NIDILRR, ACL, or HHS and you should not assume endorsement by the Federal Government.

This publication can be made available in alternative formats upon request through TransitionsACR@umassmed.edu

This is a product of Psychiatry Information in Brief. An electronic copy of this tip sheet with full references can be found at: https://escholarship.umassmed.edu/pib/vol18/iss5/1
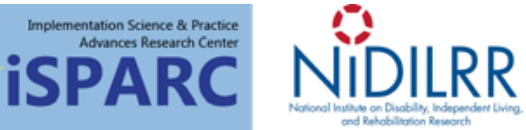
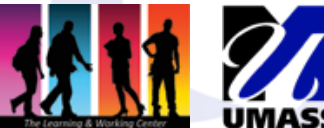

University of Massachusetts UMASS. Medical School 